\title{
High levels of interferon-gamma (IFN $\gamma$ ) in macrophage activation syndrome (MAS) and CXCL9 levels as a biomarker for IFN $\gamma$ production in MAS
}

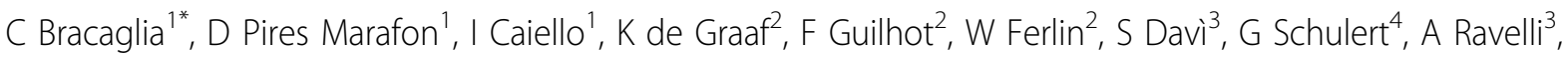 \\ A Grom ${ }^{4}$, R Nelson ${ }^{2}$, C de Min², F De Benedetti ${ }^{1}$
}

From 8th International Congress of Familial Mediterranean Fever and Systemic Autoinflammatory Diseases Dresden, Germany. 30 September - 3 October 2015

\section{Background}

A vast body of evidence in animal models points to a pivotal pathogenic role of IFN $\gamma$ in primary hemophagocytic lymphohistiocytoses (HLH). High levels of IFN $\gamma$ are also found in humans with HLH.

\section{Objectives}

Given the similarities between primary and secondary HLH (sec-HLH), including MAS, we measured levels of IFN $\gamma$, IFN $\gamma$-related chemokines (CXCL9, CXCL10, CXLC11), and IL-6 in patients with sec-HLH, and in patients with systemic Juvenile Idiopathic Arthritis (sJIA) with or without MAS at sampling and evaluated their relation to disease activity. In addition, we evaluated the correlation between serum levels of IFN $\gamma$ and of the three IFN $\gamma$ related chemokines with themselves and with laboratory parameters of disease activity in patients with active MAS.

\section{Methods}

We measured circulating levels of IFN $\gamma$, CXCL9, CXCL10, CXCL11 and IL-6 in patients with sJIA $(n=54)$ of whom 20 had MAS at time of sampling using the Luminex multiplexing assay.

\section{Results}

Levels of IFN $\gamma$ and of IFN $\gamma$-related chemokines (median $\mathrm{pg} / \mathrm{ml}(\mathrm{IQR})$ ) were markedly elevated in active MAS and

'Division of Rheumatology Ospedale Pediatrico Bambino Gesù, Department of Pediatric Medicine, Rome, Italy

Full list of author information is available at the end of the article active sec-HLH, with no significant differences between active sec-HLH (IFN $\gamma 34.7$ (23.9-170.1); CXCL9 33598 (3083-127687); CXCL10 4420 (799.7-8226); CXCL11 1327 (189-2000)) and active MAS (IFN $\gamma$ 15.4 (5.1-52.6); CXCL9 13392 (2163-35452); CXCL10 1612 (424.84309); CXCL11 564.8 (197.5-1007)). Levels in active sJIA without MAS at sampling were lower (all $\mathrm{p}$ values $2=0.47 ; \mathrm{p}=0.001)$, to a lesser extent of CXCL10 ( $\mathrm{r}=0.53$; $\left.r^{2}=0.28 ; p=0.015\right)$, and not of CXCL11 ( $\left.r=-0.04 ; p=0.886\right)$. In active MAS ferritin, neutrophils, platelets, alanine aminotransferase and lactate dehydrogenase were significantly correlated with IFN $\gamma$ and CXCL9, and to a lesser extent with CXCL10 and CXCL11; no correlation with IL-6 levels was found. In patients with active sJIA without MAS there was no significant correlation between laboratory parameters and cytokine levels (Table 1).

\section{Conclusions}

IFN $\gamma$, and IFN $\gamma$-related chemokines, levels were increased in patients with MAS compared to patients with active sJIA without MAS. The high levels of IFN $\gamma$ and of CXCL9 present in patients with active MAS were significantly correlated with laboratory parameters of disease severity. In patients with active MAS IFN $\gamma$ and CXCL9 are tightly correlated. Since CXCL9 has been shown to be induced only by IFN $\gamma$ and not by other interferons [1], our findings support the conclusion that CXCL9 is a potential biomarker of IFN $\gamma$ production in MAS. 
Table 1. Correlation of laboratory parameters of disease activity with IFN-g, CXCL9, CXCL10, CXCL11 and IL-6 in patients with MAS and in patients with active sJIA

\begin{tabular}{|c|c|c|c|c|c|c|c|c|c|c|c|}
\hline & Macrophage Activation Syndrome & $\mathrm{IFNg}$ & & CXCL9 & & CXCL1 & & CXCL1 & & IL-6 & \\
\hline & & $r^{*}$ & $p$ & $r^{*}$ & $p$ & $r^{*}$ & $p$ & $r^{*}$ & $p$ & $r^{*}$ & $p$ \\
\hline Ferritin & $8000(3158-13174)[1]$ & 0.57 & 0.014 & 0.49 & 0.041 & 0.66 & 0.002 & 0.62 & 0.023 & 0.17 & $>0.1$ \\
\hline $\mathrm{N}$ & $6.9(3.4-13.9)[1]$ & -0.64 & 0.005 & -0.61 & 0.010 & -0.37 & $>0.1$ & -0.08 & $>0.1$ & 0.09 & $>0.1$ \\
\hline$\overline{P L T}$ & $197(114-392)[1]$ & -0.53 & 0.017 & -0.52 & 0.022 & -0.58 & 0.008 & -0.22 & $>0.1$ & -0.02 & $>0.1$ \\
\hline$\overline{\mathrm{ALT}}$ & $46(18-164)[1]$ & 0.49 & 0.045 & 0.49 & 0.044 & 0.51 & 0.038 & 0.06 & $>0.1$ & -0.44 & 0.080 \\
\hline \multirow[t]{2}{*}{$\mathrm{LDH}$} & $1152(722-2135)[1]$ & 0.45 & 0.095 & 0.62 & 0.013 & 0.64 & 0.001 & 0.64 & 0.048 & 0.08 & $>0.1$ \\
\hline & Sistemic Juvenile Idiopathic Arthritis & $r^{*}$ & $p$ & $r^{*}$ & $p$ & $r^{*}$ & $p$ & $r^{*}$ & $P$ & $r^{*}$ & $p$ \\
\hline Ferritin & $214(37-1669)[1]$ & -0.27 & $>0.1$ & 0.28 & $>0.1$ & 0.27 & $>0.1$ & 0.29 & $>0.1$ & -0.12 & $>0.1$ \\
\hline $\bar{N}$ & $8.4(5.2-14.5)[1]$ & 0.30 & $>0.1$ & 0.40 & 0.061 & 0.32 & $>0.1$ & 0.40 & 0.067 & 0.28 & $>0.1$ \\
\hline$\overline{\mathrm{PLT}}$ & $444(353-544)[1]$ & 0.21 & $>0.1$ & -0.14 & $>0.1$ & -0.13 & $>0.1$ & 0.27 & $>0.1$ & 0.35 & 0.064 \\
\hline ALT & $16(11-24)[1]$ & 0.29 & $>0.1$ & 0.42 & 0.049 & 0.50 & 0.011 & 0.44 & 0.039 & 0.04 & $>0.1$ \\
\hline$\overline{\mathrm{LDH}}$ & $506(455-851)[1]$ & 0.07 & $>0.1$ & 0.49 & $>0.1$ & 0 & $>0.1$ & 0.26 & $>0.1$ & 0 & $>0.1$ \\
\hline
\end{tabular}

$\mathrm{N}=$ neutrophil count; $\mathrm{PLT}=$ platelet count; $\mathrm{ALT}=$ alanine aminotransferase; $\mathrm{LDH}=$ lactate dehydrogenase; $[1]=\mathrm{Median}(\mathrm{IQR}) ; \mathrm{r}^{*}=\mathrm{Spearman} \mathrm{r}$.

\section{Authors' details}

'Division of Rheumatology Ospedale Pediatrico Bambino Gesù, Department of Pediatric Medicine, Rome, Italy. ${ }^{2}$ Novimmune SA, Plan-les-Ouates, Geneve, Switzerland. ${ }^{3}$ University of Genoa, Istituto Giannina Gaslini, Genoa, Italy.

${ }^{4}$ Division of Pediatric Rheumatology, Cincinnati Children's Hospital Medical

Center, University of Cincinnati College of Medicine, Cincinnati, OH, USA.

Published: 28 September 2015

\section{Reference}

1. Groom JR, Luster AD: CXCR3 ligands: redundant, collaborative and antagonistic functions. Immunol Cell Biol 2011, 89(2):207-215.

doi:10.1186/1546-0096-13-S1-084

Cite this article as: Bracaglia et al:: High levels of interferon-gamma (IFN $\gamma$ ) in macrophage activation syndrome (MAS) and CXCL9 levels as a biomarker for IFN $\gamma$ production in MAS. Pediatric Rheumatology 2015 13(Suppl 1):084.

Submit your next manuscript to BioMed Central and take full advantage of:

- Convenient online submission

- Thorough peer review

- No space constraints or color figure charges

- Immediate publication on acceptance

- Inclusion in PubMed, CAS, Scopus and Google Scholar

- Research which is freely available for redistribution

Submit your manuscript at www.biomedcentral com/submit 